\title{
Infusion Reaction to Monoclonal Antibodies in Outpatient Infusion Units of a University Hospital - A Two-Year Retrospective Study
}

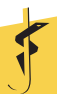

\author{
Joanna Luisa Z. Salvador, M.D.', \\ Angelita T. Garcia, M.D. ${ }^{2}$, \\ Flordeluna Z. Mesina, M.D. ${ }^{2}$,
}

\begin{abstract}
Introduction Monoclonal antibodies have revolutionized the treatment of immune-mediated inflammatory diseases (eg, rheumatoid arthritis [RA], Crohn's disease [CD], and psoriasis) as well as malignant diseases. Currently, there are about 100 monoclonal antibodies and even more are expected in the coming years. Knowledge of not only their mechanism of action but also their adverse event profile is tantamount. One of the distinctive side effects of these drugs is the potential for non-allergic and allergic infusion reactions caused by cytokine release. These adverse reactions should be monitored and managed immediately for patient welfare and safety.

General Objective To determine the prevalence of infusion reaction among patients given monoclonal antibodies at outpatient infusion units of a University Hospital, from July 2015 to July 2017.
\end{abstract}

Flordeluna Mesina

plonghema@gmail.com

Department of Medicine

University of Santo Tomas Hospital, Manila, Philippines

2 Department of Medicine, Section of Clinical Hematology University of Santo Tomas Hospital, Manila, Philippines
Methodology This is a two-year retrospective study at the University of Santo Tomas Hospital (USTH), a tertiary teaching hospital. A chart review of patients seen at the USTH Benavides Cancer Institute $(\mathrm{BCl})$ and Joint and Bone Center $(\mathrm{JBC})$ were gathered. Patients who received monoclonal antibodies namely rituximab, infliximab, bevacizumab, tocilizumab, belimumab, brentuximab, pembrolizumab, trastuzumab, pertuzumab, nimotuzumab and eculizumab from July 2015 to July 2017 were included in the study.

Results Majority of patients were in the 61 to 70 years age group $(25.7 \%)$; the median age of the population was 53 years and the majority were females $(64.9 \%)$. The most common indication for monoclonal antibody infusion is rheumatoid arthritis $(28.4 \%)$. More than one-fourth of the patients did not receive premedications $(28.4 \%$ ) but a good number $(25.7 \%)$ received at least two drugs: paracetamol plus diphenhydramine plus corticosteroids followed by $17.6 \%$ who received paracetamol plus diphenhydramine. The authors found a significant difference in the occurrence of infusion reaction between those that were given premedications compared to those who were not given premedications $(p=0.032)$. The most common monoclonal antibodies administered were rituximab $(28.4 \%)$; tocilizumab $(23 \%)$; and 
infliximab (14.9\%). However, only rituximab $(9.5 \%)$, infliximab (2.7\%) and bevacizumab (1.4\%) had infusion reactions. The overall incidence rate of infusion reaction to monoclonal antibodies was $14 \%$. The onset was within 2 hours with most infusion reactions occurring in the first cycle. Ninety percent were classified as grade 2 infusion reactions. Management of these reactions included rescue medications and brief interruption of infusion. No hospitalization nor recurrence of infusion reaction on the resumption of infusion occurred.

Conclusions: The prevalence rate of infusion reaction to monoclonal antibodies was $14 \%$ in this present single-center two-year retrospective study. All adverse events were graded mild to moderate (grade 2) in severity, and were all accordingly managed successfully in the outpatient setting.

Keywords: infusion reaction, monoclonal antibodies, prevalence

\section{INTRODUCTION}

Monoclonal antibody therapy targeted for malignancies and autoimmune diseases have shown great strides in management outcomes, whilst, adverse infusion reactions need to be addressed.

Monoclonal antibodies are developed to target a particular antigen expressed by the tumor cells, enhancing antibody-dependent cytotoxicity and tumor killing. Knowledge not only of their mechanism of action but also their their adverse event profile is tantamount. Generally, infusion of these drugs in the outpatient setting is well-tolerated; however, there are some instances when patients develop adverse reactions. One of the distinctive events is the potential for non-allergic and allergic infusion reactions caused by cytokine release. More commonly these infusion reactions are not predictable. What initially appears to be a minor reaction can eventually turn out to be deleterious. So, the safety of patients receiving therapy is of utmost importance.

The development of monoclonal antibodies has paved the way for new therapeutic strategies in treating malignancy and autoimmune diseases. The biologic medicines including monoclonal antibodies are complex molecules which are the backbone of targeted therapies. The basis of antibody-based therapy originated from the observation of antigen expression of tumor cells in the 1960s [1]. Monoclo- nal antibodies originated from a clonal expansion of antibody-producing malignant human plasma cells. According to Singh et al [2], monoclonal antibodies are fashioned to target specific cells in the body. Due to their specificity, they have the advantage of reducing other untoward effects that are caused by conventional chemotherapeutic agents.

In general, monoclonal antibodies are well tolerated. However, there are instances when acute reactions follow the infusion of these monoclonal antibodies. These may present as fever, tremor, flushing, dyspnea, itching, and changes in heart rate and blood pressure [3].

Infusion reactions are defined as any adverse event occurring in relation to drug administration and may be immediate (first hours after administration) or delayed (1-2 hours and up to 14 days after administration). Infusion reactions may also be Immunoglobulin E (lgE)-mediated or non-lgE-mediated. The latter being due to cytokine release and are associated with most monoclonal antibodies [4]. The processes by which monoclonal antibodies provoke infusion reactions are unclear. It may involve direct cytokine release, activation of the complement system and the coagulation system. However, in some studies, infusion reactions stem from innate immune response mechanism. They are not antigen-specific and do not necessitate the presence of antibodies, unlike a true antibody-mediated response. This characteristic is the reason why they do not warrant prior exposure before an infusion reaction manifests [5]. Most reactions appear immediately, but not all; generally, the more rapid the commencement, the more severe the reaction [2]. Almost all monoclonal antibodies have infusion reaction risks, but particular drugs such as rituximab, cetuximab, alemtuzumab, ramucirumab, obinutuzumab, and ofatumumab are linked with serious risk to merit special precautions [6]. Rituximab was the first monoclonal antibody accepted specifically for cancer therapy [7]. Rituximab is an anti-CD20 monoclonal antibody associated with infusion reactions in up to $85 \%$ of patients [8]. Mortality within 24 hours of rituximab infusion are documented and roughly $80 \%$ occurred in association with the first infusion [9]. Furthermore, the incidence of any grade infusion reaction during the first, fourth and eighth infusions were $77 \%, 30 \%$ and $14 \%$, respectively [2]. Trastuzumab, a monoclonal antibody specifically targeting HER2/neu positive cancer, was associated with infusion reaction and 
about $40 \%$ occurred in the first infusion. The majority occurred in the first 2 hours of infusion. On the other hand, bevacizumab, a monoclonal antibody targeting vascular endothelial growth factor, is related to infusion reaction in less than $3 \%$ of patients. Another example is cetuximab which has documented infusion reaction in approximately $3 \%$ of patients with fatal outcomes in $0.1 \%$ of patients [8].

These infusion reactions differ in severity. The reactions range from headache, mild gastrointestinal symptoms such as diarrhea, transient rash and itching to severe cytopenias, cardiac toxicity, anaphylaxis, exfoliative dermatitis and rarely life-threatening bullous toxidermias [10]. The widely accepted National Cancer Institute has formulated a classification for different types of adverse reactions associated with monoclonal antibodies. These are grade 0-5 in severity ranging from mild to severe symptoms [1 11].

Due to documented reactions, the administration of monoclonal antibodies has to be monitored closely. Certainly not a guarantee, pre-infusion medications such as antipyretics, antihistamines and corticosteroids are being used before the administration of monoclonal antibodies to decrease the likelihood of adverse reactions. Reactions of cytokine release may be managed by short-term cessation of drug infusion, administration of $\mathrm{H} 1 / \mathrm{H} 2$ inhibitors and restarting the infusion at a slower rate [6]. In rituximab, administration of the medication was also practiced to be given slowly to reduce infusion reactions. History of previous reactions should also be reviewed so as to alert caregivers of future risk of adverse effects during infusion [7].

The USTH-BCl and JBC are ambulatory units where these drugs are administered in an outpatient setting. The most common monoclonal antibodies infused in these units are rituximab, infliximab, bevacizumab, tocilizumab, belimumab, brentuximab, pembrolizumab, trastuzumab, pertuzumab, nimotuzumab and eculizumab. As part of pharmacovigilance and patient safety advocacy, the researchers would like to know the prevalence, characterize the severity of infusion reaction and describe the outcome of management given to these patients.

\section{OBJECTIVES}

This present study aims to determine the prevalence of infusion reaction in patients receiving monoclonal antibodies in the outpatient infusion units of the of the USTH from from July 2015 to July 2017 . The specific objectives include: To determine the demographic data of the study population; To classify the severity of infusion reaction based on Modified National Cancer Institute Common Terminology Criteria for Adverse Events Scale Version 3; To determine the premedications used prior to infusion of monoclonal antibodies; To determine if there is an association between the premedications given and occurrence or non-occurrence of the event; To determine the earliest time and cycle of chemotherapy when the infusion reaction developed; To describe management strategies and outcome of patients who developed infusion reactions.

\section{MATERIALS AND METHODS}

\section{Study Design and Participants}

This is a two-year retrospective study done in the USTH, a tertiary teaching hospital. A chart review of patients seen at the $\mathrm{BCl}$ and $\mathrm{JBC}$ was done. Patients who received monoclonal antibodies namely rituximab, infliximab, bevacizumab, tocilizumab, belimumab, brentuximab, pembrolizumab, trastuzumab, pertuzumab, nimotuzumab and eculizumab from July 2015 to July 2017 were included in the study. The research study proposal was approved by the UST Hospital-Institutional Review Board prior to any study-related events.

Infusion reactions were classified based on the Modified National Cancer Institute Common Terminology Criteria for Adverse Events Scale Version 3 . This is a widely accepted standard set of terminologies throughout the oncology community as the uniform classification and severity grading scale for adverse events in cancer therapy clinical trials and other oncology settings. The prevalence rate will be computed in this study.

\section{Statistical Analysis}

Data analysis was done using SPSS Statistics version 22. Quantitative variables will be presented as percentages and continuous variables will be presented as a range. Chi-square test was used to determine if there was a significant difference between the two groups being compared.

\section{RESULTS}

A total of 74 patients were included in the study, all of whom received at least 2 cycles of monoclonal 
antibody from July 2015 to July 2017 at the outpatient infusion units of the USTH. Among the study population, 10 patients developed infusion reaction which accounted for a calculated prevalence of $14 \%$.

Table 1 presents the demographic data of the study population. Nineteen patients $(25.7 \%)$ were in the 61 to 70 years age group, accounting for the majority of the population. The median age was 53 years. There were $48(64.9 \%)$ females. The most common indication for monoclonal antibody infusion among the cohort was rheumatoid arthritis $(21,28.4 \%)$.

The researchers found no significant association between age, gender and diagnosis with the occurrence of infusion reaction. ( $p$ value $=0.797,0.493$ and 0.359 ; respectively).

A majority of them received at least one premedication prior to infusion in the form of paracetamol and/or antihistamine and/or corticosteroids in 53 patients $(71.62 \%)$. The most common practice was the use of triple premedications, namely, paracetamol, diphenhydramine and corticosteroids with a frequency of $23(31.1 \%)$. Among those who were given premedications, 10 patients $(13.7 \%)$ still developed an infusion reaction. Interestingly, a significant proportion of, 21 patients $(28 \%)$ were not given any premedications. Among these cohorts, none developed infusion reaction.

The researchers found a significant difference in the occurrence of infusion reactions between those that were given premedications compared to those who were not given premedications $(p=0.032)$.

Table 3 shows the monoclonal antibodies administered to the study population. Twenty-one patients $(28.4 \%)$ received rituximab, which accounts for the majority of the population. It was also the drug where most of the infusion reaction occurred in 7 patients $(9.5 \%)$. This was followed by infliximab, accounting for a total of 11 patients (14.9\%) infused and among these, 2 patients $(2.7 \%)$ developed infusion reaction.

Table 4 classified patients according to grade of infusion reaction. In this study, it was found that $90 \%$ of the infusion reactions were grade 2 based on the Modified NCTCAE Ver 3. These patients developed chills, erythema, wheals and nausea which were immediately relieved after receiving symptomatic treatment. Only one patient who received rituximab developed a grade 3 reaction in which the patient developed wheezes and dyspnea which were managed adequately.

Table 5 notes the number of cycles when the infusion reaction manifested. Most patients developed adverse events during the first infusion $(60 \%)$.

Table 6 shows the time that infusion reaction symptoms occurred. Forty percent of reactions occurred during the first 2 hours of infusion. In this study, the onset of reaction to monoclonal antibodies was found to have a 2-hour meantime. This had a standard deviation of 1.23.

Table 1. Demographic data of patients receiving monoclonal antibody in the USTH series from July 2015 to July 2017

\begin{tabular}{|c|c|c|c|c|}
\hline \multirow[t]{2}{*}{ Demographics } & \multicolumn{2}{|c|}{$\begin{array}{l}\text { Monoclonal } \\
\text { Antibodies } \\
\text { Infusion Reaction (n,\%) }\end{array}$} & \multirow[t]{2}{*}{ Total } & \multirow[t]{2}{*}{$\mathbf{P}$} \\
\hline & Negative & Positive & & \\
\hline Age & & & & 0.797 \\
\hline 18 to 50 years old & 31 (41.84) & $4(5.41)$ & $35(47.30)$ & \\
\hline 51 to 80 years old & 32 (43.24) & $6(8.11)$ & $38(51.35)$ & \\
\hline$>81$ years old & $1(1.4)$ & $0(0)$ & $1(1.4)$ & \\
\hline Sex & & & & 0.493 \\
\hline Male & $22(29.7)$ & $4(5.4)$ & $26(35.1)$ & \\
\hline Female & $42(56.8)$ & $6(8.1)$ & $48(64.9)$ & \\
\hline Diagnosis & & & & 0.359 \\
\hline $\begin{array}{l}\text { Solid Cancers (Adenoid Cystic, Breast, } \\
\text { Colorectal, Lung and Endometrial) }\end{array}$ & $13(17.57)$ & $1(1.35)$ & 14 (18.92) & \\
\hline $\begin{array}{l}\text { Hematologic Malignancy (Lymphoma, } \\
\text { Leukemia, Plasma cell Neoplasms) }\end{array}$ & $18(24.32)$ & $5(6.76)$ & $23(31.08)$ & \\
\hline $\begin{array}{l}\text { Autoimmune Diseases (Ankylosing } \\
\text { spondilosis, Psoriatic Arthritis, SLE, } \\
\text { IBS, Scleroderma, etc.) }\end{array}$ & 33 (44.59) & $4(5.40)$ & $37(50)$ & \\
\hline
\end{tabular}


Table 2. Medications given prior to monoclonal antibody infusion in present USTH series

\begin{tabular}{lllll}
\hline Premedication & \multicolumn{2}{l}{ Monoclonal Antibody Infusion Reaction } & Total & P \\
\hline & Negative n (\%) & $\begin{array}{l}\text { Positive } \\
\text { n (\%) }\end{array}$ & \\
None & $21(28.4)$ & $0(0)$ & $21(28.4)$ & $\mathbf{0 . 0 3 2}$ \\
$\begin{array}{l}\text { With at least one } \\
\text { premedication given }\end{array}$ & $43(67.19)$ & $10(13.7)$ & $53(71.62)$ & \\
$\begin{array}{l}\text { Paracetamol } \\
\text { Corticosteroids }\end{array}$ & $0(0)$ & $1(1.4)$ & $1(1.4)$ & \\
Paracetamol, diphenhydramine & $13(1.4)$ & $1(1.4)$ & $2(2.7)$ & \\
Paracetamol, corticosteroids & $7(9.5)$ & $2(2.7)$ & $15(20.3)$ & \\
$\begin{array}{l}\text { Diphenhydramine, corticosteroids } \\
\text { Paracetamol, diphenhydramine, }\end{array}$ & $3(4.05)$ & $1(1.4)$ & $4(5.4)$ & \\
corticosteroids & $19(25.7)$ & $4(5.4)$ & $23(31.1)$ & \\
\hline
\end{tabular}

Table 3. Number and percentage of patients with and without infusion reaction according to monoclonal antibody received in the present USTH series

\begin{tabular}{lllll}
\hline & \multicolumn{2}{l}{$\begin{array}{l}\text { Monoclonal Antibody Infusion } \\
\text { Reaction (n, \%) }\end{array}$} & Total \\
\hline & Negative & Positive & & $\mathbf{0 . 1 8 9}$ \\
\hline Monoclonal Antibody & & & & \\
Belimumab & $4(5.4)$ & $0(0)$ & $4(5.4)$ & $5(6.8)$ \\
Brentuximab & $5(6.8)$ & $0(0)$ & $4(5.4)$ & \\
Bevacizumab & $3(4.1)$ & $1(1.4)$ & $1(1.4)$ & \\
Eculizumab & $1(1.4)$ & $0(0)$ & $11(14.9)$ & $1(1.4)$ \\
Infliximab & $9(12.2)$ & $2(2.7)$ & $2(2.7)$ & \\
Nimotuzumab & $1(1.4)$ & $0(0)$ & $2(2.7)$ & $21(28.4)$ \\
Pembrolizumab & $2(2.7)$ & $0(0)$ & $17(23)$ & \\
Pertuzumab & $2(2.7)$ & $0(0)$ & $6(8.1)$ & \\
Rituximab & $14(18.9)$ & $7(9.5)$ & $0(0)$ & \\
Tocilizumab & $17(23)$ & $0(0)$ & \\
Trastuzumab & $6(8.1)$ & & & \\
\hline
\end{tabular}

Table 4. Number and percentage of grading of monoclonal antibody infusion reaction present in the USTH series

$\begin{array}{llllll}\text { Grade 1 } & \text { Grade 2 } & \text { Grade 3 } & \text { Grade 4 } & \text { Grade 5 } \\ \text { reaction } & \text { reaction } & \text { reaction } & \text { reaction } & \text { Total }\end{array}$

Monoclonal

Antibody

\begin{tabular}{|c|c|c|c|c|c|c|}
\hline Bevacizumab & $0(0)$ & $1(10)$ & $0(0)$ & $0(0)$ & $0(0)$ & $1(10)$ \\
\hline Infliximab & $0(0)$ & $2(20)$ & $0(0)$ & $0(0)$ & $0(0)$ & $2(20)$ \\
\hline Rituximab & $0(0)$ & $6(60)$ & $1(10)$ & $0(0)$ & $0(0)$ & 7 (70) \\
\hline Total & 0 & 9 (90) & 1 (10) & 0 & 0 & $10(100)$ \\
\hline
\end{tabular}

The management of infusion reactions included administration of medications for hypersensitivity reaction. Among the medications given, seven patients received hydrocortisone $(70 \%)$, three were given diphenhydramine $(30 \%)$, one patient received metoclopramide (10\%), one patient received ranitidine $(10 \%)$ and one was given hyoscine-n-butyl bromide $(10 \%)$. One patient was given salbutamol nebuliza- 
Table 5. Number and percentage of monoclonal antibody infusion reaction according to the number of cycles received in the present USTH series

\begin{tabular}{lllllllll}
\hline $\begin{array}{l}\text { Cycle of } \\
\text { Infusion }\end{array}$ & $1^{\text {st }}$ cycle & $2^{\text {nd }}$ cycle & $3^{\text {rd }}$ cycle & $4^{\text {th }}$ cycle & $5^{\text {th }}$ cycle & $6^{\text {th }}$ cycle & $7^{\text {th }}$ cycle & Total \\
\hline $\begin{array}{l}\text { Monoclonal } \\
\text { Antibody }\end{array}$ & & & & & & & \\
$\begin{array}{l}\text { Bevaci- } \\
\text { zumab }\end{array}$ & $1(10)$ & $0(0)$ & $0(0)$ & $0(0)$ & $0(0)$ & $0(0)$ & $0(0)$ & $1(10)$ \\
$\begin{array}{l}\text { Infliximab } \\
\text { Rituximab }\end{array}$ & $1(10)$ & $0(0)$ & $0(0)$ & $0(0)$ & $1(10)$ & $0(0)$ & $0(0)$ & $2(20)$ \\
Total & $6(60)$ & $1(10)$ & $1(10)$ & $0(0)$ & $0(0)$ & $0(0)$ & $1(10)$ & $7(70)$ \\
\hline
\end{tabular}

Table 6. Number and percentage of monoclonal antibody infusion reaction according to time of onset

\begin{tabular}{lllllll}
\hline Time of Onset & $<$ hour & $\mathbf{2}$-2 hours & $\mathbf{2}$-3 hours & $\mathbf{2 3 - 4}$ hours & $\mathbf{2 4}$ hours & Total \\
\hline $\begin{array}{llllll}\text { Monoclonal Antibody } \\
\text { Bevacizumab }\end{array}$ & $0(0)$ & $0(0)$ & $0(0)$ & $0(0)$ & $1(10)$ & $1(10)$ \\
Infliximab & $0(0)$ & $1(10)$ & $1(10)$ & $0(0)$ & $0(0)$ & $2(20)$ \\
Rituximab & $0(0)$ & $3(30)$ & $2(20)$ & $0(0)$ & $2(20)$ & $7(70)$ \\
Total & $0(0)$ & $4(40)$ & $3(30)$ & $0(0)$ & $3(30)$ & $10(100)$ \\
\hline
\end{tabular}

tion due to wheezes, with subsequent discontinuation of infusion. Two patients had a brief interruption of infusion and one patient had extended infusion time.

In this study, all patients who developed infusion reaction were observed, monitored and managed in the outpatient clinic and none required hospitalization. All patients had a good response to medical management to control the infusion reactions.

\section{DISCUSSION}

The salient finding in this present two-year study derived from a single-center university hospital ambulatory care setting, is the occurrence of a $14 \%$ prevalence of infusion reactions for those 74 patients administered with monoclonal antibodies in the oncologic and rheumatologic specialized services.

A majority of the patients were females in the older population, however, there were no associations with the onset of infusion reactions to age, sex and diagnosis. These present data were notably consistent with those published from elsewhere [12].

In addition, it was found that most patients' premedications included paracetamol, diphenhydramine and corticosteroids. The data obtained in the study were seen to be consistent with other investigations where the most common premedications generally provided to patients were antihistamines and paracetamol [17]. Whilst found in this present study that a majority of patients had a grade 2 severity of reaction (eg, erythema, headache and chills), another local study also showed that 4 out of 5 patients taking rituximab developed grade 2 infusion reactions [21]. From elsewhere studies, grade 2 reactions were also more common $[22,23]$ though some highlighted that grade 3 or 4 hypersensitivity reaction also occurred $[24,25]$. Coherent from elsewhere studies too $[2,3]$, the timing of occurrence of infusion reaction in this study appears to be within 120 minutes post infusion, though some may be delayed up to 24 hours [2].

In this present study, most of the infusion reactions occurred during the first cycle of infusion, as was noted in another local study [21], and from another series [3]. Along with these, Choquette and colleagues [26] found that the incidence then varied from $1.8 \%$ to $3.2 \%$ between infusion numbers two and eight. Fewer than $1 \%$ developed infusion related reaction on the $8^{\text {th }}$ cycle of rituximab treatment in a study by Vogel et al.[7]. Mild to moderate infusion reactions can be controlled by administration of supportive therapy or a temporary discontinuation of infusion [3].

\section{CONCLUSION}

The prevalence of monoclonal antibodies infusion reaction in the USTH ambulatory care setting is $14 \%$ in a 2-year period. Twenty-eight percent of patients that received monoclonal antibody infusion had 
rheumatoid arthritis. Infusion reaction was more common in females and in advanced age. Infusion reaction occurred within the first 2 hours of infusion and most occur during the first cycle. Majority of the reactions were classified as grade 2 based on NCTCAE Version 3. Premedications provided to patients were paracetamol, diphenhydramine and corticosteroids. Finally, it was found in the investigation that the patients who developed monoclonal antibody reaction generally tolerated the reaction after giving rescue medications. None required hospitalization nor recurrence of an infusion reaction.

The researcher recommends further studies regarding infusion reaction to include any comorbidities of the patient such as a history of allergy to account for the possibility of this risk factor in the development of infusion reaction. Furthermore, we recommend improvement in the documentation of the occurrence of infusion reactions, presentation, vital signs and physical examination of patients before, during and after infusion. 


\section{REFERENCES}

1. Scott A, Wolchock J, Old L. Antibody therapy of cancer. Nature Reviews Cancer. 2012;12:278-87.

2. Singh A, Singh DK, Bhoria U. Infusion reactions associated with use of biologic medicines in cancer therapy. Oncocytology. 2014;4:10-18.

3. Muallaoglu S, Disel U, Mertsoylu H. et al. Acute infusion reactions to chemotherapeutic drugs: a single institute experience. Journal of BUON. 2013 Jan-Mar; 18(1):261-7.

4. Corominas M, Gastaminza G, Lobera T. Hypersensitivity Reactions to Biological Drugs. Journal of Investigational Allergology and Clinical Immunology. 2014;24(4):212-25.

5. Asselin B. Immunology of infusion reactions in the treatment of patients with acute lymphoblastic leukemia. Future Oncology. 2016;12 (13):1609-21.

6. Joeger $M$. Prevention and handling of acute allergic and infusion reactions in oncology. Annals of Oncology. 2012;23(10):313-19.

7. Vogel WH. Infusion Reactions: Diagnosis, Assessment, and Management, Clinical Journal of Oncology Nursing. 2010;14(2):10-21.

8. Cmelak A, Lordick F, Borner M, et al. Reactions in Clinical Trials and Beyond: The US and EU Perspectives. Oncology Journal. 2009;23(2): 18-25.

9. Atmar J. Review of the Safety and Feasibility of Rapid Infusion of Rituximab. Journal of Oncology Practice. 2010 Mar;6(2):91-93.

10. Baldo B. Adverse events to monoclonal antibodies used for cancer therapy: Focus on Hypersensitivity Responses. Oncoimmunology. 2013 Oct 1;2(10):e26333.

11. National Cancer Institute (2006). Common terminology criteria for adverse events v3.0 (CTAE). [Cited April 21, 2008]. Available from: http://ctep.cancer.gov/forms/ CTCAEv3.pdf

12. Gowda A, Goel R, Berdzik J, Leichman CG, Javle M. Hypersensitivity reactions to oxaliplatin: Incidence and management. Oncology (Williston Park). 2004: 18:1671-5.

13. Wilkes G. Managing drug infusion reactions: Focus on cetuximab monoclonal antibody therapy. Clinical Journal of Oncology Nursing. 2008;12(3):530-2.

14. Hainsworth JD, Litchy S, Burris HA III, et al. Rituximab as first-line and maintenance therapy for patients with indolent non-Hodgkin's lymphoma. J Clin Oncol. 2002;20:4261-7.

15. Vose JM, Link BK, Grossbard ML, et al. Phase II study of rituximab in combination with $\mathrm{CHOP}$ chemotherapy in patients with previously untreated, aggressive non-Hodgkin's lymphoma. J Clin Oncol. 2001;19:389-97.

16. Coiffier B, Lepage E, Briere J, et al. CHOP chemotherapy plus rituximab compared with $\mathrm{CHOP}$ alone in elderly patients with diffuse large B-cell lymphoma. N Engl J Med. 2002;346:235-42.

17. Schwartzberg LS, Stepanski EJ, Fortner BV, et al. Retrospective chart review of severe infusion reactions with rituximab, cetuximab, and bevacizumab in community oncology practices: assessment of clinical consequences. Supportive Care in Cancer. 2008; 16:393-8.

18. George Jr TJ, Laplant KD, Walden EO, et al. Managing cetuximab hypersensitivity-infusion reactions: incidence, risk factors, prevention, and retreatment. J Support Oncol. 2010;8(2):72-7.

19. Hansen NL, Chandiramani DV, Morse MA, et al. Incidence and predictors of cetuximab hypersensitivity reactions in a North Carolina academic medical center. J Oncol Pharm Pract. $2011 ; 17(2): 125-13$.

20. Siena S, Glynne-Jones R, Adenis A, et al. Reduced incidence of infusion-related reactions in metastatic colorectal cancer during treatment with cetuximab plus irinotecan with combined corticosteroid and antihistamine premedication. Cancer 2010;1 16(7):1827-83.

21. Montoya JE, Luna HG, Vergara NG. et al. Incidence of infusion-related reaction to monoclonal antibody rituximab: a national kidney and transplant institute experience. Ann Acad Med Singapore. 2012 Mar;41(3):125-6.

22. Zhang $H$, Berezov $A$, Wang $Q$, et al. ErbB receptors: from oncogenes to targeted cancer therapies. J Clin Invest. 2007; $117(8): 2051-8$.

23. Mendelsohn J, Baselga J. Epidermal growth factor receptor targeting in cancer. Semin Oncol. 2006;33(4):369-85.

24. Chung $\mathrm{CH}$, Mirakhur B, Chan $\mathrm{E}$, et al. Cetuximab induced anaphylaxis and IgE specific for galactose alpha- 1,3-galactose. N Engl J Med. 2008;358(1 1):1109-17.

25. George Jr TJ, Laplant KD, Walden EO, et al. Managing cetuximab hypersensitivity-infusion reactions: incidence, risk factors, prevention, and retreatment. J Support Oncol. 2010;8(2):72-77.

26. Choquette, Faraawi, Chow, et al. Incidence and Management of Infusion Reactions to Infliximab in a Prospective Real-world Community Registry. The Journal of Rheumatology. 2015;42(7): $1105-11$.

(c) (i) Open Access This article is licensed under a Creative Commons Attribution 4.0 International License, which permits use, sharing, adaptation, distribution and reproduction in any medium or format, as long as you give appropriate credit to the original author(s) and the source, provide a link to the Creative Commons license, and indicate if changes were made. The images or other third party material in this article are included in the article's Creative Commons license, unless indicated otherwise in a credit line to the material. If material is not included in the article's Creative Commons license and your intended use is not permitted by statutory regulation or exceeds the permitted use, you will need to obtain permission directly from the copyright holder. To view a copy of this license, visit http://creativecommons.org/licenses/ by/4.0/. 